\title{
Orient com a sutura
}

\author{
Aleix Bonfill \\ Universitat Autònoma de Barcelona. Departament de Filosofia \\ aleixbon@gmail.com
}

\section{Resum}

Aquest article tractarà del potencial de millora i transformació, tant pel que fa a qualitat de vida personal com col-lectiva, que ofereixen les tradicions orientals. Sembla que Occident —o el model de civilització occidental— ha arribat a un punt crític en què l'anomenada postmodernitat ha abocat els individus a una quotidianitat marcada per l'ansietat, la incertesa, l'apatia, la fragmentació..., sense proporcionar-los eines efectives per conduir-s'hi. La conquesta de la felicitat, l'amor, la saviesa i la pau gairebé no figura en l'agenda del dia de ningú. Aquí parlarem d'algunes pràctiques i actituds que poden ajudar a reprendre les regnes de la pròpia existència i, alhora, mirarem d'esbossar com aquestes «noves» perspectives, assumides col-lectivament, podrien proporcionar una sortida del moment de confusió històrica actual.

Paraules clau: Salvador Pàniker; ètica de la transformació; felicitat; postmodernitat.

\section{Abstract}

This paper will deal with the potential for improvement and transformation, both in terms of quality of life personally and collectively offered by Eastern traditions. It seems that the West, or the model of Western civilization, has reached a critical point where the socalled post-modernism has led individuals to an existence marked by anxiety, uncertainty, apathy, fragmentation... without providing them with effective tools to cope with all that. The conquest of happiness, love, wisdom and peace is hardly on the agenda of anyone. Here we talk of some practices and attitudes that can help to regain the reins of our own existence, while we will outline how these «new»perspectives, taken at a collective level, could provide a way out of the current historical moment of confusion.

Keywords: Salvador Pàniker; Ethics of transformation; Happiness; Postmodernism. 


\section{Sumari

$\begin{aligned} \text { Meditar } & \text { Salut integral } \\ \text { Ėtica d'aquí i ara } & \text { Conclusió } \\ \text { En societat } & \text { Bibliografia }\end{aligned}$

The 'I think' which Kant said must be able to accompany all my objects, is the I breathe' which actually does accompany them.

WILLIAM JAMES

Aquest article tractarà del potencial de millora i transformació, tant pel que fa a qualitat de vida personal com col-lectiva, que ofereixen les tradicions orientals. Sembla que Occident —o el model de civilització occidental — ha arribat a un punt crític en què l'anomenada postmodernitat ha abocat els individus a una quotidianitat marcada per l'ansietat, la incertesa, l'apatia, la fragmentació... sense proporcionar-los eines efectives per conduir-s'hi. La conquesta de la felicitat, l'amor, la saviesa i la pau gairebé no figura en l'agenda del dia de ningú. Aquí parlarem d'algunes pràctiques i actituds que poden ajudar a reprendre les regnes de la pròpia existència $i$, alhora, mirarem d'esbossar com aquestes «noves» perspectives, assumides col-lectivament, podrien proporcionar una sortida del moment de confusió històrica actual.

En aquest recorregut, em remetré sovint a la filosofia «retroprogressiva» de Salvador Pàniker. Per a una primera caracterització d'aquesta noció:

Suele decirse que Occidente, con la modernidad, apuesta por la carta unidimensional del progreso; lo cual es cierto, y de ahí que con el derrumbe del concepto de progreso haya surgido la crisis del concepto de modernidad. Pero lo que se dice menos es que cabe la conciliación entre el progreso (secularización/racionalización/complejidad creciente) y el regreso (sensibilidad místico/ estética, aproximación al origen, recuperación de la no-dualidad originaria). (Pàniker, 2008)

Així doncs, el nostre equilibri rauria en el redescobriment d'una actitud o pràctica que a Occident fa temps que ha estat oblidada, que consisteix, senzillament, a aturar-se i no fer absolutament res, només observar com ens arriba a costar l'abandonar tota activitat i escoltar amb atenció desinteressada el fluir impersonal del present. Romandre una estona en l'aquí i ara, sense identificarnos amb els judicis, inquietuds i hàbits que de seguida afloren en la ment de cadascú.

Aquest fet, realitzat a consciència i regularment, és un acte (no-acte) gairebé revolucionari. Al llarg dels anys, la cultura occidental, i en conseqüència també els individus que la conformen, han tendit a moure's pel que Pàniker anomena la unidimensionalitat del progrés. Per trobar l'origen de l'oblit de l'altra cara místico-silenciosa de la moneda potser caldria remuntar-se fins a Parmènides. Des que aquest establís que hi havia quelcom que es podia dir de 
l'ésser, la verborrea no ha cessat, i els equívocs, tampoc. Els discursos s'han anat amuntegant, contradient, especialitzant, complexificant. Algunes d'aquestes conceptualitzacions diverses han permès a l'home d'apropiar-se el món tot transformant-lo al seu parer, des de possibilitar la genètica i les telecomunicacions fins a potenciar les grans massacres perpetrades per nosaltres, els "éssers de raó». Les barbaritats han esdevingut perquè l'home ha viscut abocat a l'exterior, $\mathrm{i}$ ha disposat tots els mitjans (inclòs el llenguatge) per materialitzar els seus capritxos i intentar lluitar contra els seus temors. Ha considerat el seu egoisme com quelcom d'inamovible i natural, i en termes generals ha dedicat poques energies a apropiar-se i transformar el seu cor.

És cert que a Occident també ha existit aquest ideal, però la majoria de les vegades ha quedat merament en ideal perquè no s'ha disposat dels coneixements necessaris per avançar en aquesta pràctica. Així mateix, els filòsofs sovint han posat al descobert el paper actiu del llenguatge en la conducta humana, però ho han hagut de fer irremeiablement valent-se del mateix llenguatge, i a l'hora de proposar alternatives, no han sabut ben bé on buscar o s'han limitat, com Wittgenstein, a assenyalar de lluny un camí massa estrany i vague.

Com diu Gianni Vattimo, «el problema és que no som prou nihilistes». Ens costa confiar a fons en el no-ser (l'«allò sobre el que hom ha de callar» de Wittgenstein), i així en l'actualitat romanem paralitzats en el primer estadi nihilista que Nietzsche repudiava. Orient proporciona les pautes concretes per penetrar en el silenci i d'aquesta manera accedir a l'interior d'un mateix. Si un va avançant en aquesta direcció, el nihilisme primitiu es va convertint progressivament en quelcom de positiu i fructífer. I a partir d'aquí tot és més facil.

El acceso a la sabiduría no conceptual apenas se concibe en Occidente. Porque en Occidente, al menos desde Kant, no podemos deshacernos del pensamiento, es decir, no podemos deshacernos del lenguaje. Ahora bien, el lenguaje es algo aprendido. ¿Y si lo desaprendiéramos? A esa posibilidad, en Oriente, la llaman meditación. Con lo cual la meditación pasa a ser una deconstrucción del pensamiento. (Pàniker, 2008)

\section{Meditar}

A continuació intentarem caracteritzar breument un tipus de meditació (en anglès anomenada mindfulness i que sovint es tradueix per «atenció o consciència plena») que no parteix de cap creença ni premissa teòrica bàsica, sinó simplement de la voluntat de romandre una estona en el present i d'observar amb curiositat la pròpia ment. És una pràctica sobretot conreada per les diferents tradicions budistes, que des de fa unes dècades s'ha estès a un ritme insòlit arreu del món. També està tenint molt èxit en ambients laics en què es practica regularment com a mètode terapèutic, d'autoconeixement i millora personals, com ara hospitals, presons, escoles, etc. Recentment, psicòlegs i 
neurocientífics han mostrat un interès creixent per aquestes tècniques, tant pels beneficis evidents que proporcionen com per les coincidències entre les teories de la neurociència i les observacions descrites per experts meditadors.

Mindfulness es, en sí misma, algo muy simple y familiar, algo que todos nosotros hemos experimentado en numerosas ocasiones de nuestra vida cotidiana. Cuando somos conscientes de lo que estamos haciendo, pensando o sintiendo, estamos practicando mindfulness. Lo que sucede es que habitualmente nuestra mente se encuentra vagando sin orientación alguna, saltando de unas imágenes a otras, de unos a otros pensamientos. Mindfulness es una capacidad humana universal y básica, que consiste en la posibilidad de ser conscientes de los contenidos de la mente momento a momento. Es la práctica de la autoconciencia. El primer efecto de la práctica de mindfulness es el desarrollo de la capacidad de concentración de la mente. El aumento de la concentración trae consigo la serenidad. Y el cultivo de la serenidad nos conduce a un aumento de la comprensión de la realidad (tanto externa como interna) y nos aproxima a percibir la realidad tal como es.

Por una parte existe el componente básico, la característica fundamental de mindfulness, que consiste en mantener la atención centrada en la experiencia inmediata del presente. Es, por decirlo así, la instrucción eje que hay que seguir; ser conscientes de lo que sucede en el presente inmediato. Y el segundo componente es la actitud con la que se aborda el ejercicio del primer componente, es decir, cómo se viven esas experiencias del momento presente. (Simon, 2010)

Per assolir el primer component bàsic de mantenir l'atenció centrada en el present, és comuna la recomanació de fixar-se en la respiració natural, tal com entra i surt del cos sense interferir en el seu ritme. Així, quan la ment divaga una vegada i una altra, suaument s'acompanya l'atenció de retorn a la respiració. La clau, doncs, està en la continuïtat de la pràctica i en la persistència.

Això entronca amb el segon component, el de l'actitud amb què es viuen les experiències en meditació. Aquesta actitud ha de reunir alhora una llista oberta de qualitats positives, entre les que poden figurar l'acceptació, la curiositat, l'obertura, la confiança, el despreniment, l'equanimitat (no jutjar), la paciència, etc. El més freqüent és que en començar a meditar la ment es trobi en l'estat oposat, plena de judicis, tensions, ansietat, etc. Aleshores no es tracta de negar el que hi ha i lluitar contra això per voler canviar-ho, sinó precisament de reconèixer-ho i acceptar-ho amb obertura, despreniment, sense jutjar-se, etc.

Si un s'habitua a veure's sota aquesta llum, qualsevol circumstància es converteix en una oportunitat per aprendre d'un mateix. Pàniker ho explica des d'un altre punt de vista:

Más allá del ego está lo que los hindúes llaman el Testigo, es decir, el margen de libertad que contempla «desde fuera» la película de la propia vida. Este testigo es lo que los budistas denominan Vacío. Este Testigo no anula el ego ni las servidumbres del ego. Este Testigo es el que ve el ego, pero sin identificarse 
con él. [...] Ello es que el Testigo se encuentra ya presente en cualquier estado de conciencia; sólo se trata de reconocerlo. Y en eso, sólo en eso, consiste la meditación. (Pàniker, 2008)

\section{Ètica d'aquí i ara}

En su mayoría, los filósofos se han complacido en ignorar los problemas prácticos de la toma de decisiones en tiempo real, haciendo referencia al simple hecho de que todos somos finitos y olvidadizos, y que tenemos que apresurarnos a emitir juicios, como un elemento de fricción, real pero irrelevante, en la maquinaria que ellos tratan de describir. Es como si se tratara de dos disciplinas: la ética propiamente dicha, que tiene a su cargo la tarea de calcular los principios que determinan lo que el agente ideal debe hacer bajo cualquier circunstancia y, al mismo tiempo, la disciplina menos interesante y «simplemente práctica» de la «moral entendida como primeros auxilios» $\mathrm{o}$, dicho de otro modo, “¿Qué hacer hasta que el doctor de filosofía llegue?»; esta segunda disciplina tratará, en términos simples y directos, de cómo tomar decisiones sobre la marcha bajo la presión del tiempo. (Dennett, 1999)

Dennett es lamentava així de la rapidesa amb què en la vida quotidiana s'han de prendre les decisions, per la qual cosa disminueix notablement la possibilitat de reflexionar sobre les diferents opcions de tria i contrastar-les amb els ideals ètics. Així mateix, les tradicions orientals assenyalen que, encara que no ens n'adonem, quasi totes les accions i decisions, per petites i insignificants que siguin, sempre tenen conseqüències ètiques (o kàrmiques), amb la qual cosa podem estar alimentant contínuament una cadena de despropòsits sense ser-ne conscients.

Des de la neurociència, Damasio explica en la mateixa línia que el que creiem que són deliberacions lògiques i purament racionals vénen sempre acompanyades per un substrat emocional que les condiciona en un grau molt alt. En la presa de decisions, els seus estudis mostren com en realitat és una part més primitiva de la ment d'una persona (el que ell anomena «el marcador somàtic») el que inclina la balança cap a alguna de les opcions, i que és a posteriori que intervé el pensament representacional que genera la il.lusió de raó pura i d'identitat personal.

Així doncs, per influir en la majoria de decisions que prenem, primer cal estar més atent a les entranyes que a les idees. La meditació és l'eina òptima per contactar amb aquests processos biològics més subtils que de bones a primeres romanen en l'inconscient. L'observació sostinguda del comportament de la ment i la constatació del seu veritable funcionament condueixen a la saviesa, al coneixement directe i experiencial; advé vipassana: visió de les coses tal com són. Significa reconèixer les pròpies creences com a creences, els propis desitjos com a desitjos, els propis temors com a temors, i així retirar la lent amb què hom interpreta el món i desactivar la força amb què aquests factors confonen la ment inconscient. I amb la saviesa, arriba la compassió. 
Des d'un altre angle, Pàniker coincideix:

[...] Tampoco la racionalización universalista de la doctrina nos satisface mucho. Ningún principio ético a priori, ningún imperativo categórico, sintoniza hoy con nuestra sensibilidad democrática y relativista.

[...] No hay una ley divina o natural que pueda ser obedecida o desobedecida. El taoísmo tiene que ver con el arte de acertar, no con la obediencia a una ley; tiene que ver con la empatía y con el obrar indeliberado y desapegado que coincide con la espontaneidad de la natura (tzu-jan). El taoísmo criticó al confucionismo por no advertir que la compasión y el altruismo brotan espontáneamente en quienes han realizado su auténtica naturaleza. Las leyes son hijas de la desconfianza y del temor. Pero ya Nietzsche intentó construir un sistema de valores que no se basara en el miedo — sin advertir, dicho sea de paso, que la «voluntad de poder» de su «superhombre» era ya hija del miedo, pues quien no teme a sus vecinos no desea dominarlos- En todo caso, la alternativa al miedo es la citada empatía que no puede ser legislada por ningún código moral. Así William Blake decía que «Cristo no se atenía a regla alguna, sino que sólo seguía sus impulsos». (Pàniker, 2008)

Una altra perspectiva atractiva és la visió implícita en el budisme pel que fa a la culpabilitat o maldat de les persones. Ningú és jutjat com a pecador o criminal, sinó que els actes negatius (els quals no ho són en termes absoluts, sinó en funció de la infelicitat de la qual neixen i de la que causen) expressen la ignorància de l'agent que els duu a terme: ignorància de la naturalesa de la ment i de la realitat. En el fons, fins i tot els actes més atroços es veuen com a manca de cultiu de mindfulness o atenció plena, i així tothom és digne de compassió i de rebre l'ensenyança de Buda per al benefici de tots els éssers. Sovint també es considera aquesta ignorància com una mateixa entitat que s'expressa en els diferents individus, i així s'afavoreix l'empatia envers la persona «afectada» i l'efectivitat en el tractament de la generalitzada "patologia».

Acabarem aquest apartat tot recordant que a l'Etica Nicomaquea d'Aristòtil, un dels textos fundacionals de l'ètica occidental, s'identifica l'home contemplatiu com l'ideal de vida, tant en termes de virtut com de felicitat. Tanmateix, la majoria de filòsofs i professors de filosofia, començant pel mateix Aristòtil, han prescindit d'aquest ideal, fonamentalment a causa d'una comprensió massa superficial de la pràctica contemplativa. Aquesta mala comprensió sovint esgrimeix els arguments que no totes les persones estan capacitades per portar una vida «intel.lectual» pura, i que les condicions d'interdependència en què es desenvolupa la vida humana impedeixen dedicar-se a la contemplació. Però des d'Orient arriba una rèplica: tothom és apte per a la contemplació, ja que aquesta consisteix a entrenar la facultat universal de l'atenció. Així, no cal ser eremita per cultivar-la, sinó que és possible (i encara més necessari!) fer-ho enmig de la polis. Tan sols cal trobar uns 45 minuts al dia en una cambra tranquil.la, jeure-hi, i no moure's, no esforçar-se, no preocupar-se, només tancar els ulls, respirar i observar. També es pot intentar estar present de la 
mateixa manera durant les accions quotidianes (a la dutxa, fregant, prenent un cafe). A la llarga, la paciència i la perseverança en aquest sentit operen un gran canvi. Un canvi cap al despertar i cap a la joia innombrable.

\section{En societat}

En la antigua sociedad china, había dos tradiciones «filosóficas» que desempeñaban papeles complementarios: confucionismo y taoísmo. Mientras la primera se ocupaba de la socialización de la conciencia (aprendizaje de las convenciones lingüísticas, éticas, jurídicas y rituales que hacen posible la convivencia), la segunda se encargaba de reparar los daños causados por la socialización, recuperando la creativa espontaneidad reprimida por los convencionalismos. Entre ambas tradiciones componían un auténtico circuito retroprogresivo. Una coexistencia de contrarios que está en la base de la sabiduría.

Ello es que la verdadera educación consiste tanto en aprender como en desaprender. Alan Watts ha señalado que es una verdadera catástrofe cultural que Occidente carezca de una institución equivalente al taoísmo. Eso hace de Occidente una cultura unilateral y enfermiza. Por eso, lo que en Oriente son sabidurías, en Occidente han de ser terapias. (Pàniker, 2008)

En un altre lloc, Pàniker suggereix que la institució occidental que més s'ha apropat al rol de descodificador de la consciència ha estat l'anarquisme. No obstant, la varietat d'opinions dintre d'aquest corrent, les circumstàncies històriques, i el fet que en termes generals l'anarquisme ha estat més enfocat a canviar el món exterior abans que l'interior, han contribuït al fet que a Occident la transformació de la consciència hagi quedat relegada a cercles marginals i esotèrics. Per això és necessària una voluntat pública, oberta i crítica per tal de fomentar l'exploració personal en aquesta direcció.

Hace falta, sí, una «Educación para la Ciudadanía». Hace falta una paideia laica para inculcar los valores de la democracia, la solidaridad, el pluralismo, el respeto al prójimo; para transmitir los lenguajes de las ciencias, el conocimiento de la historia y de las tradiciones. Ahora bien, en lo que concierne a la última actitud frente a la vida, no hay más maestro que uno mismo. Lo dijo hace veinticinco siglos el Buda: «No aceptéis lo que oigáis decir; sed lámparas para vosotros mismos. (Pàniker, 2008)

Recentment, certs col-lectius d'activistes dels anomenats «antisistema» o «altermundistes» (per diferenciar-los dels que s'identifiquen amb les etiquetes «sistema» o "món normal») han rescatat l'eslògan de Gandhi: «sigues el canvi que vols veure al món». I és que aquesta revolució individual, i de retruc, social, ja no és una possibilitat, sinó una necessitat objectiva per a la supervivència de la humanitat i del planeta. Sovint es té la il.lusió que de la història se'n va aprenent i que així no es repeteixen els episodis obscurs que han anat trasbalsant la vida de les persones al llarg dels segles. Però sota diferents formes, el patró cec i egoista que regeix el funcionament «normal» de la ment i les societats continua expressant-se dia rere dia. 
El segle XX, amb dues guerres mundials i centenars de milions de morts en conflictes bèl.lics, ètnics, ideològics, etc., semblava haver marcat una fita insuperable en la disfunció espiritual de l'home. Però l'avidesa, l'aversió, la ignorància... continuen actuant arreu. El nou mil.lenni, doncs, no s'ha quedat enrere, $\mathrm{i}$ ha començat amb atemptats terroristes a gran escala, guerres a Irak i Afganistan, evidenciant la disfunció del model de capitalisme vigent amb l'esclat de les crisis climàtica, alimentària, energètica, financera, etc. L'estructura egòtica sobre la qual es fonamenta aquesta dinàmica de despropòsits no canviarà si continuem esperant que arribi no se sap qui o què $i$ recondueixi el rumb dels esdeveniments. Fins a l'actualitat, les persones i els col-lectius que han volgut millorar primerament el món exterior tard o d'hora han acabat segrestats o vençuts per alguna màscara de l'ego, com la cobdícia, l'odi, la por, l'autocomplaença, etc. Per això cal una transformació més propera, més global, més íntima.

Sembla que la solució, doncs, passa perquè cadascú s'adoni i es responsabilitzi de les petites misèries de la seva vida, $i$ que es faci càrrec de com aquestes afecten negativament a si mateix i a qui l'envolta. Amb el temps, un arriba a desfer-se d'aquesta càrrega viciosa i a reconèixer la consciència d'unitat originària, el sentiment d'interconnexió amb tot el que existeix. No es tracta d'una creença, una postura filosòfica o un desig innocent, sinó l'expressió de la constatació vivencial a la qual han al-ludit durant mil-lennis les ensenyances orientals, a saber, que tota dualitat (subjecte/objecte, bo/dolent, jo/no-jo) és només l'aparença amb què l'ego de cadascú (un constructe sociolingüístic amb el qual ens identifiquem) classifica els fenòmens. Amb aquesta profunda comprensió de la realitat, dessota o més enllà de les paraules i dels condicionaments mentals heretats que alimenten l'ego, batega la pau i la llibertat, la generositat $i$ la gratitud.

Uno sospecha que el ego es un invento (reciente y provisional) de la evolución destinado a desaparecer. $\mathrm{O}$ al menos, a ser superado. Es ya un hecho establecido que la disminución del egocentrismo es proporcional al aumento de la capacidad de empatizar con el prójimo. He ahí la base antropológica de la moral. Así, una nueva cooperación entre seres humanos que hubieran trascendido su ego podría equivaler a la revolución eucariota que dio origen a la vida multicelular. La humanidad se habría convertido en lo que los biólogos llaman un superorganismo. Lo cual sería el resultado de una evolución cultural (mucho más rápida que la genética) y una prueba de «inteligencia». (Pàniker, 2008)

\section{Salut integral}

La idea de una mente separada del cuerpo parece asimismo haber modelado la manera peculiar en la que la medicina occidental enfoca el estudio y el tratamiento de las enfermedades. La escisión cartesiana impregna tanto la investigación como la práctica médica. Como resultado, las consecuencias psicológicas de las enfermedades del cuerpo propiamente dicho, las denomi- 
nadas enfermedades reales, se suelen pasar por alto y sólo se tienen en cuenta en segunda consideración. Más desatendida todavía es la situación inversa, los efectos sobre el cuerpo propiamente dicho del conflicto psicológico. ¡Qué fascinante pensar que Descartes contribuyó efectivamente a modificar el curso de la medicina, ayudó a desviarla del enfoque organísmico, de la mente en el cuerpo, que imperó desde Hipócrates hasta el Renacimiento! ¡Qué enojado habría estado Aristóteles con Descartes, si lo hubiera sabido! (Damasio, 2006)

La dualitat il.lusòria a què feiem referència anteriorment, doncs, també afecta a la relació que mantenim amb els nostres cossos. "Els nostres cossos» és només una manera de parlar, ja que en realitat no existeix tal separació entre el suposat amo (la identitat personal) i la seva propietat (el cos biològic). Això no obstant, l'aferrament als processos de pensament i sentiment que donen continuïtat a la idea de «jo» porta a tractar com a «no-jo» tot allò que no és aquests pensaments, entre d'altres coses la resta del propi cos. Així, aquest esquinçament psicològic fa que l'individu visqui enclaustrat en el seu cap i que, com diuen les tradicions orientals, l'energia deixi de fluir amb naturalitat per tot l'organisme. D'aquesta manera sorgeixen tensions, bloquejos emocionals, $\mathrm{i}$ afeccions psicosomàtiques més greus.

Per avançar cap a l'harmonia cos-ment cal adonar-se que el patró psicològic que Descartes sintetitzà en el "penso, per tant existeixo» i que es troba en l'arrel de la conducta humana "normal» és només una part de la nostra consciència, i que és possible superar la tirania de la "substància pensant» a través de la consciència del «jo respiro» a què apunta la citació que encapçala aquest article.

Si definim l'estrès com el neguit de voler estar en un lloc o moment en el que no s'està en el present immediat, trobem que un altíssim nombre de persones pateix diàriament d'estrès, en diferents graus i circumstàncies. El més freqüent és que en la majoria de casos el mateix afectat no reconegui que es troba en una situació d'aquestes característiques. Sigui com sigui, aquesta actitud mental de resistència interna a l'aquí i l'ara disposa el cos en actituds agressives, temoroses, agitades etc., la qual cosa impregna tots els àmbits de l'activitat humana i impedeix de realitzar-s'hi amb tot el potencial del que hom és capaç.

Així, la pràctica mèdica occidental ben sovint també es troba imbuïda d'aquesta actitud. Tant des del punt de vista del metge com del pacient, la malaltia és vista com un mal, un enemic al qual cal derrotar, i així es «fa la guerra» contra el càncer, l'obesitat, etc. En canvi, seria més profitós si hom aprengués a reconvertir la resistència i rebuig inicials en acceptació i obertura, de tal manera que el tractament passés a ser una cerca de reequilibri i cooperació enlloc de conflicte entre salut/malaltia, metge/pacient, jo/«el meu cos», etc. En aquest context, el metge estaria obert al sofriment del pacient i requeriria de la seva implicació activa. Per la seva banda, el pacient hauria d'assumir la seva part de responsabilitat en el seu sofriment, tot mirant d'estar alerta i receptiu als canvis que succeeixen dintre seu. Així s'anirien dissolent les barre- 
res psicològiques que obstrueixen el procés i afegeixen més dolor al ja existent, $i$ es passaria a estimular la plena eficàcia dels diversos factors que intervenen en la guarició.

En els últims anys, ha anat augmentant l'interès científic sobre el paper que juga la ment en la velocitat i qualitat de la recuperació de l'organisme. Comparant dos grups de pacients d'una mateixa malaltia però amb disposicions mentals diferents (per exemple, un grup control versus un grup de meditadors), és possible observar les diferències entre el comportament dels respectius sistemes immunològics. A mesura que els estudis científics avancin en aquesta línia i vagin confirmant aquest fenomen, és possible que s'arribi a un nou paradigma en què el sistema sanitari adopti mètodes i mesures que afavoreixin l'equilibri ment-cos, una vinculació afectiva més beneficiosa entre metge i pacient, i una exhortació a la ciutadania a tenir cura també de la seva vida mental tenint en compte la rellevància d'aquesta en la salut global de l'organisme.

\section{Conclusió}

Sembla que, després d'un viatge estrany i convuls, hem tornat altre cop al «coneix-te a tu mateix» de Delfos. Però pel camí hem après i construït moltes coses útils i meravelloses, en gran mesura gràcies al desenvolupament intel.lectual d'Occident. Es tracta que, pel bé de tots, aquests fruits i tots els que sorgiran de les nostres capacitats humanes estiguin al servei d'una consciència més sàvia i compassiva, l'accés a la qual han mantingut viu sobretot a Orient. Arribats en aquest punt, doncs, la contraposició "Occident/Orient», com les altres dualitats aparents, ha de donar pas a una comprensió més profunda, holista i integradora del que és l'ésser humà.

La consciència de la qual hem parlat no és quelcom abstracte ni res que es pugui comprendre intel.lectualment, sinó la manifestació tangible d'una exploració interior que acaba transformant la ment que en un principi havia emprès la cerca. El panorama esperançador que s'anuncia per al final del procés no és una promesa ni una utopia, sinó una potencialitat real a la qual només es pot accedir des de l'aquí i ara, a base d'estar atent i en pau amb el moment present tal com és (i no tal com creiem o volem que sigui).

Per això aquesta cerca no es pot imposar a ningú. No pot néixer del rebuig ni la por, sinó d'una motivació clara i sincera. Un només pot encoratjar els altres a emprendre-la i confiar que convencerà algú dels beneficis d'aprofundir en el silenci. Aleshores tan sols queda esperar que les bones llavors comencin a multiplicar els seus fruits.

\section{Bibliografia}

DAmASIO, A. (2006). El error de Descartes. Barcelona: Ed. Crítica, col-lecció Drakontos Bolsillo.

DennetT, D. (1999). La peligrosa idea de Darwin. Barcelona: Galaxia GutembergCírculo de Lectores. 
Goleman, D. (2007). Les emocions i la salut. Diàlegs amb el Dalai Lama sobre el budisme $i$ les ciències del cervell. Lleida: Pagès Editors.

KaBATT-Zinn, J. (2007). La práctica de la atención plena. Barcelona: Ed. Kairós.

PÀnIKer, S. (2008). Asimetrías. Apuntes para sobrevivir en la era de la incertidumbre. Barcelona: Ed. Debate.

Simón, Vicente M. (2010). "Mindfulness y neurobiología». Revista de Psicoterapia, vol. XVII, núm. 66/67.

VARELA, F. (2005). De cuerpo presente. Las ciencias cognitivas y la experiencia humana. Barcelona: Ed. Gedisa. 